\title{
Quantification of diffuse myocardial fibrosis in patients with resistant hypertension undergoing renal denervation versus hypertensive controls - preliminary results
}

Adelina Doltra ${ }^{*}$, Jan-Hendrik Hassel ${ }^{1}$, Daniel Messroghli ${ }^{1}$, Bernhard Schnackenburg${ }^{2}$, Philipp Stawowy ${ }^{1}$, Rolf Gebker ${ }^{1}$, Christopher Schneeweis ${ }^{1}$, Alexander Berger ${ }^{1}$, Eckart Fleck' ${ }^{1}$, Sebastian Kelle ${ }^{1}$

From 17th Annual SCMR Scientific Sessions

New Orleans, LA, USA. 16-19 January 2014

\section{Background}

Renal Denervation (RDN) is a novel therapy for patients with resistant hypertension. Its cardiac effects at followup are currently unknown. On the other hand, T1 mapping permits the assessment of myocardial extracellular volume (ECV), a parameter proposed to quantify diffuse myocardial fibrosis and independently associated with mortality and hard cardiovascular events. Our aim was to study the effects of RDN on ECV at 6-month follow-up.

\section{Methods}

14 patients with resistant hypertension undergoing RD (RD group) and 4 resistant hypertensive patients not undergoing RD (control group) were prospectively included. A $1.5 \mathrm{~T}$ cardiac MR including T1 mapping preand post-contrast was performed before the RD procedure and at 6-month follow-up in both groups. Blood hematocrit was determined at both time points. Images were post-processed using commercial software (Qmass, Medis
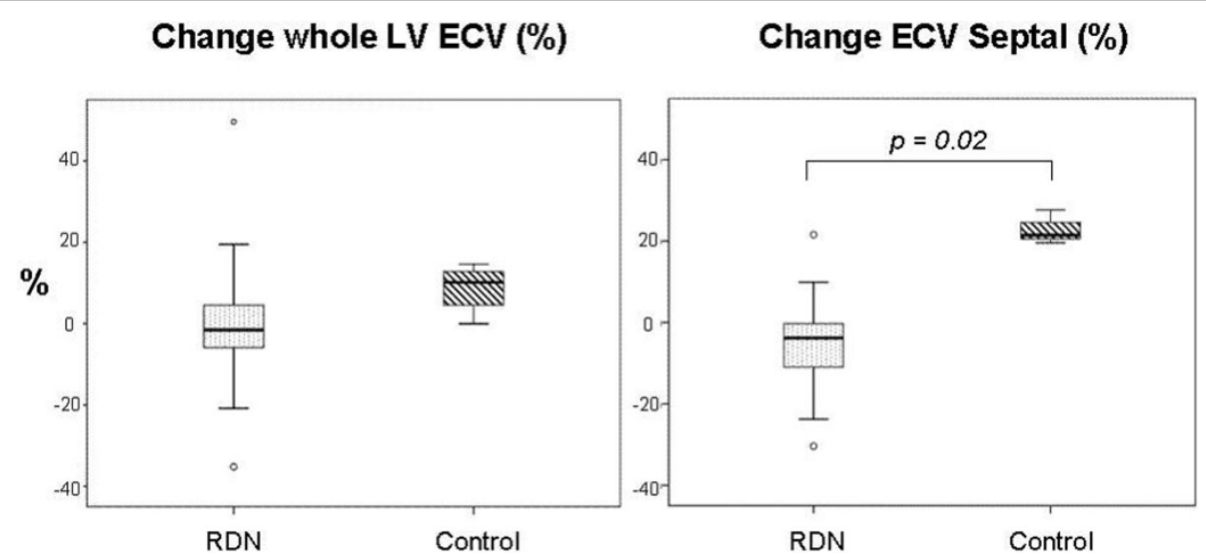

Figure 1 Percent ECV-change baseline versus 6-months follow-up in patients with resistant hypertenstion undergoing renal denervation and hypertensive controls.

${ }^{1}$ Cardiology, German Heart Institute Berlin, Berlin, Germany

Full list of author information is available at the end of the article 
Medical Solutions, the Netherlands), and whole left ventricle (LV) ECV and septal ECV at baseline and at 6-month follow-up were quantified as follows: $\mathrm{ECV}=$ (1-hematocrit $) * \lambda$, where $\lambda=(1 / \mathrm{T} 1$ myocardium post-contrast $-1 /$ T1 myocardium pre-contrast)/(1/T1 blood post-contrast 1/T1 blood pre-contrast).

\section{Results}

No significant differences in whole LV ECV or septal ECV were observed between baseline and 6-month follow-up in the RD group. In contrast, control patients presented an increase in whole LV ECV and septal ECV at 6-month follow-up which did not reach statistical significance $(\mathrm{p}=0.14$ and $\mathrm{p}=0.11$, respectively). When the results were expressed as a \% of change versus baseline, the \% change of ECV septal was significantly different between the RDN and control groups $(-5.4 \pm 14.4$ $(-3.8)$ vs $22.9 \pm 4.2(21.5)$, respectively, $\mathrm{p}=0.02$; results expressed as mean \pm SD (median)) (Figure 1).

\section{Conclusions}

Extracellular space could increase at follow-up in nonRDN patients, potentially reflecting a progressive increase in myocardial fibrosis content. This effect is not observed in RDN patients, suggesting a beneficial effect of RDN in delaying this fibrotic progression. Our results are preliminary and need to be confirmed in a larger population.

\section{Funding}

None.

\section{Authors' details}

${ }^{1}$ Cardiology, German Heart Institute Berlin, Berlin, Germany. ${ }^{2}$ Philips

Healthcare Systems, Hamburg, Germany.

Published: 16 January 2014

doi:10.1186/1532-429X-16-S1-065

Cite this article as: Doltra et al:: Quantification of diffuse myocardial fibrosis in patients with resistant hypertension undergoing renal

denervation versus hypertensive controls - preliminary results. Journal of Cardiovascular Magnetic Resonance 2014 16(Suppl 1):065.
Submit your next manuscript to BioMed Central and take full advantage of:

- Convenient online submission

- Thorough peer review

- No space constraints or color figure charges

- Immediate publication on acceptance

- Inclusion in PubMed, CAS, Scopus and Google Scholar

- Research which is freely available for redistribution

Submit your manuscript at www.biomedcentral.com/submit 